\title{
Graduate Student Award
}

\section{Biosecurity implications of the synthesis of pathogenic viruses}

\author{
Aleksandr Rabodzey, MSc \\ Doctoral candidate, Division of Biological Engineering \\ Associate, Security Studies Program \\ Room 3-252 \\ Massachusetts Institute of Technology \\ Cambridge, MA 02139 \\ USA \\ rabodzey@armscontrol.ru
}

Aвstract. Recent peer-reviewed reports of in vitro syntheses of small viruses raise the possibility of misapplying modern biotechnologies to the creation of new smallpox virus, not simply to the malicious manipulation of existing samples. While it would require great effort and significant financing, a smallpoxfrom-scratch project would seem likely to be feasible, as would some other pathogen-from-scratch projects. Efforts to prevent such work - or, failing prevention, to detect it - might be enhanced in a number of ways.

$\mathrm{T}$ he terrorist attacks of 11 September 2001 in the United States and subsequent attacks worldwide have demonstrated that determined groups can possess levels of sophistication and organization allowing them to inflict considerable damage. The postal anthrax attacks of October 2001 - at this writing still unattributed - demonstrated even greater sophistication, in this case microbiological sophistication, though perhaps only in an individual, not an organization.

The range of threats that a terrorist group might pose is wide, but those associated with nuclear, chemical, or biological weapons are considered especially serious. Each of these threats, in turn, is different in its operative features and destructive potential as well as in the kind of strategy required to counter it. Development of strategies to deal with these threats requires thorough analysis. Deserving special consideration is a new microbiological possibility: the synthesis of pathogens usable by terrorists.

The postal anthrax attacks, which killed five and alerted millions, had been anticipated by occasional small successes and at least one frightening failure, an unsuccessful 1993 attack in Tokyo by the Aum Shinrikyo religious cult. ${ }^{1}$ The US government in 2003 spent nearly six billion dollars financing defense against bioterrorism - more than the National Institutes of Health received that year for its cancer programs. ${ }^{2}$

A difficulty inherent in biological-threat reduction is effecting reasonable degrees of control over pathogens themselves and the facilities that do or could work with them. ${ }^{3}$ Advances in ordinary civilian biotechnology continuously open new possibilities potentially exploitable by terrorists, ${ }^{4}$ a fact without analogy in the far more static fields of chemical- and nuclear-threat reduction. Developing biological weapons does not require the heavy-industrial infrastructure necessary to obtain and process chemical or nuclear materials and could be much more difficult to detect. Most of the work could be done in a laboratory, using equipment and materials relatively easy to obtain. Development of pathogenic agents may be well within reach of a subnational terrorist group, even if they do not have governmental support.

I first consider the synthesis of pathogenic organisms in general and then focus on the smallpox virus. I then suggest an approach to the viral-synthesis security problem, an approach designed to accommodate at least one projection of near-term biotechnological progress. 
Table 1. Viruses and their genome lengths.

\begin{tabular}{llc}
\hline \hline \multicolumn{1}{c}{ Virus family } & Pathogenic example $(\mathrm{s})$ & Genome length $(\mathrm{kb})$ \\
\hline DNA viruses & & 3 \\
$\begin{array}{l}\text { Hepadnaviruses } \\
\text { Poxviruses }\end{array}$ & $\begin{array}{l}\text { Hepatitis B virus } \\
\text { Variola (smallpox virus) }\end{array}$ & 200 \\
RNA viruses & Poliomyelitis virus \\
Picornaviruses & $\begin{array}{l}\text { Encephalomyocarditis } \\
\text { virus }\end{array}$ & 7.5 \\
Flaviviruses & $\begin{array}{l}\text { Hepatitis C virus } \\
\text { Ebola hemorrhagic fever } \\
\text { Filoviruses }\end{array}$ & 7.8 \\
Retroviruses & $\begin{array}{c}\text { Human immunodeficiency } \\
\text { virus (HIV) }\end{array}$ & 10 \\
\hline
\end{tabular}

$\mathrm{kb}=$ kilobases

\section{The challenge to terrorists}

To deploy a biological weapon, terrorists would have to succeed in three major tasks: getting a promising pathogen, producing it in usable quantities, and dispersing it in a way that would constitute an attack, whether this take the form of "mass destruction," "mass distraction," random murder, targeted extortion, or economic sabotage. Each of these tasks presents a certain challenge, different for different agents. For example, Bacillus anthracis could be relatively easy to obtain from natural reservoirs and straightforward to produce in large volumes. That said, developing an effective dispersal mechanism for this agent would require a very fine aerosol or powder. With other agents, especially ones contagious human-to-human, dispersal would be less problematic. In contrast, the major challenge presented by a decision to spread smallpox is the first one: getting the virus. Variola, the smallpox virus, no longer has a natural reservoir, and the only acknowledged sources - repositories in Russia and the United States - are under safeguards thought reliable enough to prevent diversion.

\section{Recent advances}

In 2001, Viktor Volchkov and colleagues from the Institute of Virology in Marburg, Germany, and the Université Claude Bernard Lyon 1 recovered Ebola virus (EBOV) from complementary DNA (cDNA) assembled from three pieces approximately 6,000 nucleotides each; ${ }^{5}$ the native EBOV genome is 18,959 nucleotides in length, or about 19 kilobases $(\mathrm{kb})$, as listed in Table 1.
In August 2002, E. Wimmer and colleagues from the State University of New York, Stony Brook, reported that they had synthesized the poliomyelitis virus. They used over a hundred nucleotide fragments, each about 70 nucleotides long, all purchased from a mail-order biotechnological company, to construct viral antisense DNA, based on a known sequence. All materials needed for the synthesis were - and are - available through the Internet.

In June 2003, Y.V. Svitkin and N. Soenenberg reported cell-free synthesis of Encephalomyocarditis virus. ${ }^{6}$

Protocols are constantly improving, making the increasingly efficient synthesis of increasingly complex viruses hard not to foresee. In November 2003, a group headed by J. Craig Venter successfully demonstrated a protocol cutting from months to weeks the assembly time for a bacteriophage, a small virus parasitic for bacteria. ${ }^{7}$ In the cited studies by Wimmer and Svitkin and their colleagues, viruses were created outside a cell - an improvement over earlier methods, such as the one described by Volchkov and colleagues, in which a virus was created using cellular machinery. Outside-acell protocols allow the synthesis of larger viruses. A recent overview of biotechnology progress ${ }^{8}$ predicts that by the year 2010 a scientist working alone will be able to sequence or assemble roughly $10^{10}$ bases per day - two orders of magnitude more than that now. It seems likely that newer protocols could be used to synthesize a variety of viruses, including agents adaptable to weaponization, though traditional culture techniques would remain more practical in all cases calling for ordinary or easily obtained pathogens.

In the following sections, I will focus on the Variola virus and consider various factors that might potentially complicate its synthesis or, on the contrary, make its synthesis easier.

\section{Complexity of the virus}

Variola is a more complex virus than the poliomyelitis virus. Variola's genome consists of about 200,000 base pairs, 26 times larger. The protocol used to assembly the poliomyelitis virus required three years of work but, according to Wimmer, ${ }^{9}$ could be reduced to take about six months. Still, with time necessary for synthesis tending to increase linearly with genome length, making Variola with anything like the poliomyelitis protocol would be an exceedingly slow process. Moreover, Variola's DNA is so long that its synthesis 


\section{Rabodzey}

would likely encounter another limitation, a formidable one but not necessarily an insurmountable one.

The currently most advanced polymerase chain reaction (PCR) machines produce about $2-4 \mathrm{~kb}$ oligonucleotide pieces. To overcome losses on each PCR step one would need to generate "extra" DNA by transfection of bacteria with plasmid containing this piece. Transfection efficiency decreases as introduced plasmid or vector size increases. Transfected bacteria would not likely produce DNA of more than $50 \mathrm{~kb},{ }^{10}$ and many pieces would be much smaller. That said, adaptation of different techniques might be possible; cloning genomic DNA into yeast artificial chromosomes (YACs) might allow insertions as large as 400,000 or even $1,000,000 \mathrm{~kb}^{.1}$ If bacterial transfection remained necessary, then to overcome smallpiece problem one would need to "suture" small fragments together to make larger ones, using special enzymes, entirely unlike what was done in Wimmer's work. As daunting as this sounds at first hearing, scientists capable of getting to this problem would probably be able to solve it.

While few would doubt that virus assembly techniques will continue to improve, predicting the pace and impact of improvement is another matter. For example, Venter's protocol might not well work in the case of the smallpox virus since this method generates a significant number of mutations, and these are likely to be critical in so large and complex a virus.

Another factor distinguishing Variola from previously synthesized viruses is its reproduction requirments. After entering a cell, smallpox DNA requires a specific viral protein, RNA polymerase, to transcribe its DNA and initiate viral assembly. No experimental data on the development of this protein exists at this point. Some suspect that the synthesis of this RNA polymerase may turn out to be more complicated than the synthesis of DNA itself. ${ }^{12}$ These difficulties, nonetheless, seem surmountable. Proteins important for assembly may be synthesized from viral DNA using routine recombinant techniques, as done in the Ebola synthesis case. This would require introduction of additional expression vectors with corresponding genes (already available in the total DNA sequence) in the same cells. Alternatively, the necessary proteins may be obtained from viruses similar to the smallpox virus: the cowpox or monkeypox viruses.

The yield from any individual transfection procedure is low, and the yield from any combination even lower. An easier approach could be to bypass transfection by taking a similar virus, like Vaccina, the cowpox virus, which is readily available in nature, and altering its genome to match Variola.

Finally, the Variola genome, as published, may not accurately describe the smallpox virus. The faithful rendering of mistakes could make an assembled virus less potent than expected - even innocuous. Accuracy of the published genome is impossible to verify without having access to the actual virus, so checking the potency of a synthetic copy would be the only way to make sure that the sequence was tolerably correct. That said, the chance that published information is cripplingly incorrect seems rather small, judging from the accuracy of other published genomes and the rarity with which spontaneous mutations affect the virulence of native pathogens. Further, since publication of the smallpox-virus genome sequence was intended to promote work on a vaccine, and even on anti-viral agents, the secret introduction of disabling distortions seems implausible. The publishers would have had to prejudge the identity of the most promising antibody or anti-viral targets, so as to justify disseminating a sequence they had deceptively "attenuated." If they had known enough to do so confidently then they would surely have directed the development community to the identified targets and may have decided to publish only the chosen sequences.

\section{Costs and skills}

The cost of laboratory equipment and reagents would likely be a limiting factor for individuals or small marginally financed groups but not for more determined organizations.

Viral DNA can be assembled from basic building blocks - oligonucleotides. These, in turn, can be assembled from four basic nucleotides. Oligonucleotide sequences of various lengths are available from a number of biotechnology companies by mail order for pennies per base. Oligonucleotides of the kind used in the synthesis of the poliomyelitis virus cost about twentyfive cents per base. ${ }^{13}$ This means that oligonucleotides for the 200-kb Variola would cost about \$50,000.

Building with longer sequences would reduce synthesis time but might jeopardize a covert operation, since the longer the nucleotide sequence ordered by mail 


\section{Synthesis of pathogenic viruses}

Table 2. Necessary equipment and their initial costs.

\begin{tabular}{lr}
\hline \hline DNA synthetizer & $\$ 125,000$ \\
DNA sequencer & $\$ 145,000$ \\
PCR equipment & $\$ 45,000$ \\
Other expenses & $\$ 100,000$ \\
Total & $\$ 415,000$ \\
\hline
\end{tabular}

the easier to match it against a database of select-agent genomes. Since a matching system would necessarily be sensitive to the possibility of illicit activity, falsepositive results would be rather common, suggesting that the research community would already know if such matching were underway; it seems not to be. The alternative to mail-ordering longer sequences would be to produce oligonucleotides in the laboratory, and this would require additional equipment and therefore might not reduce overall costs. At the same time, in comparison to what is needed to synthesis DNA, producing oligonucleotides in laboratory would not add much complexity to the operation.

Regardless of whether oligonucleotides were mailordered or produced locally, a laboratory attempting to synthesize a virus would have to purchase a DNA synthesizer, a DNA sequencer, and a number of less expensive devices, including a thermocycler, centrifuges, hoods, and sterilization equipment. Total spending on equipment and chemicals might come to between four- and five-hundred thousand dollars (Table 2).

Personnel costs are not included in this total, though they could be substantial, depending on location in a high-wage or low-wage economy. Committed terrorists, even suicide-terrorists, must eat and sleep, and scientists known in their communities but working covertly there must appear to live normally. Mercenary scientists could be quite expensive to employ - and to keep silent.

The expenses associated with viral synthesis are significant but not especially prohibitive. Cost might be a barrier to small groups but would not limit a determined government or sophisticated conspiracy. Aum Shinrikyo spent millions of dollars on a biologicalweapon development program; their frustrations were not financial.

The procedures involved in viral synthesis require a professional knowledge of biology and a confirmed proficiency in biotechnology. Competent assistants could do much day-to-day work, but something like a smallpox-from-scratch project would require considerable innovation, not just at its inception but repeatedly, long-term. Recruiting and retaining a capable director and a clever, committed, and behaviorally stable staff is hard enough in normal science; it must be even harder in apocalyptic terrorism. While staffing would seriously challenge any covert viral-synthesis project, the global availability of training-program graduates - many of them unemployed - and of the technology they were trained to use could simplify matters into a feasible range.

\section{Proposals for control and prevention}

The development of policies effectively preventing or at least detecting - the illicit synthesis of smallpox or other pathogens will not be easy. The equipment and skills required are exactly those used in standard biotechnological facilities throughout the world. According to one major accounting firm, Ernst and Young, about 4,300 biotechnology companies were in operation worldwide in 2003, around 1,500 in the United States and more than 1,800 in Europe. ${ }^{14}$ How many of these companies are capable of artificially synthesizing long DNA pieces is anyone's guess; undoubtedly some are, as would be some number of laboratories owned by institutions and governments.

Matters are complicated further by American refusal to support a verification protocol for the Biological and Toxin Weapons Convention (BWC), though the protocol as negotiated would not have been as strong as biosecurity advocates had hoped and was never designed to find dangerous activities taking place within the territory of signatory governments but without the knowledge of those governments. The verification protocol negotiated for the BWC would never have been sufficient, but something like it has always been necessary, if for no other reason than to discourage governments from sponsoring smallpoxfrom-scratch projects on the old arms-racing theory that regional rivals could not be shown to lack such projects.

Suitable for incorporation into a future verification protocol yet still cleanly outside the immediate BWC context would be a measure making all facilities capable of developing artificial organisms continually accountable for their activities, in the same way that banks must always be able to say how and where assets 


\section{Rabodzey}

under their control are invested, though they may need to report these facts formally only periodically. Such a rule would generate a registry that would eventually have to be worldwide. Protection of intellectual property and trade secrets would make the guarding of the registry itself an interesting issue; protection of national-security interests might at least initially seem to be a component of this issue, though states genuinely honoring their BWC obligations would have a hard time explaining their concerns.

However, this measure might just concentrate surveillance efforts where they are least likely to be needed. Quite different advances - analogues of remote sensing through "national technical means" (NTM) - could help complicate nefarious efforts. National governments might require DNA analyzers to be fitted with modules able to compare processed sequences to select pathogen sequences and report certain matches, but not others, to a global-positioning satellite, with inspectors then dispatched. A module like this would assist in determining if the machinery was being used to process smallpox or some other virus but would still allow investigational privacy, as it would not permit outsider access to other information. The nature of biological research makes it difficult to determine the exact nature of work carried out in a laboratory even with intrusive inspections. The approach suggested here would start an inspection with a specific question prompted by actual evidence.

Another measure that could be used to detect efforts to synthesize a virus would be the development of a system that would allow the companies that orginially supplied oligonucleotides to analyze their orders later on. Even though viral synthesis does not require ordering long oligonucleotides, an analysis might still be useful for uncovering dangerous activity. As with other monitoring efforts, mechanisms would be needed to protect commercially sensitive information and to preserve industry cooperation.

Though implementation of such measures would eventually require the cooperation of various national and international institutions, waiting for a consensus of these institutions is not necessary. Instead, the United States could take a lead in developing new monitoring mechanisms and employing them domestically. After that, it could invite other countries to join in and provide advice and assistance.

\section{Next questions}

Can camelpox or monkeypox proteins be used for smallpox-virus replication? Can long DNA fragments be cloned using bacteria or YACs? Can large viruses be synthesized using available techniques, like those introduced by Venter's laboratory? These questions are easy to pose, and their answers could easily transform surveillance, both in its urgency and in its methods. Somewhere in every responsible government, someone must understand why.

The author thanks Paul Podvig, PhD, Center for Arms Control, Energy, and Environmental Studies, Moscow Institute of Physics and Technology; Theodore Postol, PhD, Security Studies Program, MIT; and Kathleen Vogel, PhD, Peace Studies and Science-and-Technology Studies, Cornell University, for their generous support and advice. The author likewise thanks Rocco Casagrande, PhD, Director, The Center for Homeland Security, Abt Associates, Inc., Cambridge, Massachusetts, without whose many comments and invaluable suggestions this article would not have been possible.

\section{References}

1. Kyle B. Olson, "Aum Shinrikyo: Once and Future Threat?" Emerging Infectious Diseases, 5:4, 1999.

2. US Department of Homeland Security, Defending Against Biological Terrorism, Office of the Press Secretary, 5 February 2002.

3. Gaudioso, J and Salerno, R.M. "Biosecurity and Research: Minimizing Adverse Impacts” Science, 304(5671): 687, 30 April 2004.

4. James B. Petro, Theodore R. Plasse, Jack A. McNulty, "Biotechnology: Impact on Biological Warfare and Biodefense," Biosecurity and Bioterrorism, 1:3, 2003.

5. V.E. Volchkov et al., "Recovery of infectious Ebola virus from complementary DNA: RNA editing of the GP gene and viral cytotoxicity," Science, 2001, 291(5510): 1965-9.

6. Y.V. Svitkin N. Sonenberg, "Cell-free synthesis of encephalomyocarditis virus," Journal of Virology, 2003, 77(11): 6551-5.

7. Hamilton O. Smith, Clyde A. Hutchison, III, Cynthia Pfannkoch, and J. Craig Venter, "Generating a synthetic genome by whole genome assembly: $\varphi$ X174 bacteriophage from synthetic oligonucleotides", PNAS 2003, 100: 15440-15445; published online before print as 10.1073/pnas.2237126100.

8. Robert Carlson, "The Pace and Proliferation of Biological Technologies," Biosecurity and Bioterrorism, 2003, 1: 3. 


\section{Synthesis of pathogenic viruses}

9. A. Pollack, "Traces of terror: the science; scientists create a live polio virus," New York Times, 12 July 2002.

10. BD Bioscience Retroviral Gene Expression System Manual.

11. D.P. Judge, N.J. Biery, D.R. Keene, et al., "Evidence for a critical contribution of haploinsufficiency in the complex pathogenesis of Marfan syndrome," Journal of Clinical Investigation, July 2004, 114(2): 172-81.

12. Pollack.

13. Oswel Scientific, $<$ http://www.oswel.com/code/en/ product_high_through.htm $>$.

14. Beyond Borders, Ernst and Young, 2003. 